\title{
Use of quantitative shotgun proteomics to identify fibronectin 1 as a potential plasma biomarker for clear cell carcinoma of the kidney
}

\author{
Akira Yokomizo $^{\mathrm{a}, *, 1}$, Michiko Takakura ${ }^{\mathrm{b}, 1}$, Yae Kanai ${ }^{\mathrm{c}}$, Tomohiro Sakuma $^{\mathrm{d}}$, Junichi Matsubara ${ }^{\mathrm{b}}$, \\ Kazufumi Honda ${ }^{\mathrm{b}}$, Seiji Naito ${ }^{\mathrm{a}}$, Tesshi Yamada ${ }^{\mathrm{b}}$ and Masaya Ono ${ }^{\mathrm{b}}$ \\ ${ }^{a}$ Department of Urology, Graduate School Medical Sciences, Kyushu University, Fukuoka, Japan \\ ${ }^{\mathrm{b}}$ Division of Chemotherapy and Clinical Research, National Cancer Center Research Institute, Tokyo, Japan \\ ${ }^{\mathrm{c}}$ Division of Molecular Pathology, National Cancer Center Research Institute, Tokyo, Japan \\ ${ }^{\mathrm{d}}$ BioBusiness Group, Mitsui Knowledge Industry, Tokyo, Japan
}

\begin{abstract}
Background: Early detection would be one of the most effective means to improve the outcome of renal cell carcinoma (RCC). We searched for a new plasma marker for RCC using a label-free quantitative shotgun proteomics method.

Methods: Plasma proteins were digested by trypsin, and the resulting peptides were analyzed by 2-Dimensional Image Converted Analysis of Liquid chromatography mass spectrometry (2DICAL). An identified biomarker candidate was subjected to validation using the Amplified Luminescent Proximity Homogeneous Assay (AlphaLISA).

Results: Among a total of 23,407 independent MS peaks, we found that the mean intensity of 59 peaks significantly differed between 20 clear cell RCC patients and 20 healthy controls. MS/MS spectra from 16 of the 59 peaks matched the amino acid sequences of the fibronectin 1 ( $F N 1)$ gene product. The increased plasma level of FN1 in RCC patients was validated in a cohort of in 77 patients and 130 healthy controls $(p<0.0001)$.

Conclusions: The FN1 is considered to be a promising biomarker candidate for clear cell RCC. Furthermore, AlphaLISA is an alternate to the conventional enzyme-linked immunosorbent assay and should prove useful for the rapid validation of biomarker candidates.
\end{abstract}

Keywords: Renal cell carcinoma, tumor marker, proteomics, fibronectin

\section{Introduction}

The incidence of renal cell carcinoma (RCC) has been increasing since 1980s in western countries as well as Japan and is now the third most common malignancy of the urinary tract following prostate and bladder cancers [1]. Although early detection and treatment are considered to be the most effective methods to improve the outcome of patients with any cancer, RCC

\footnotetext{
* Corresponding author: Akira Yokomizo, Department of Urology, Graduate School of Medical Sciences, Kyushu University, 3-11 Maidashi, Higashi-ku, Fukuoka 812-8252, Japan. Tel.: +81 92 642 5603; Fax: +81 92642 5618; E-mail: yokoa@uro.med.kyushuu.ac.jp.

${ }^{1}$ These two authors contributed equally to this work.
}

patients often do not manifest clinical symptoms and receive medical attention until their tumors progress to advanced stages [2-4]. Recently, ultrasound and CT scan can detect smaller renal tumors. However, we do need an effective plasma biomarker for differentiating the malignant from the benign when a patient was found with a small renal mass, which cannot be easily judged from ultrasound or CT scan [5]. Therefore, it is necessary to identify the tumor marker better than neither ultrasound test nor CT scan in diagnosing small renal mass. If a sensitive but non-invasive blood assay that can detect early-stage RCC were available, it would greatly improve the curative rate of RCC.

Shotgun proteomics is an established technique in which whole proteins are enzymatically digested into a large array of small peptide fragments followed 
by direct analysis by liquid chromatography and mass spectrometry (LC-MS). We previously developed software named 2DICAL that can provide a quantitative dimension to shotgun proteomics [6]. 2DICAL can accurately align different LC-MS data and compare the protein content of a theoretically unlimited number of samples without isotope labeling [7]. 2DICAL is highly advantageous methods in clinical studies that require the comparison of a statistically sufficient number of patient samples [8]. Using 2DICAL, we were able to identify diagnostic biomarkers for endometrial and pancreatic cancers $[7,8]$ and predictive biomarkers for hematologic toxicities and therapeutic efficacy of gemcitabine treatment to patients with advanced pancreatic cancer [9].

In this study we compared the plasma proteome between RCC patients and healthy controls using 2DICAL with the aim to identify a new diagnostic biomarker that can be used for a blood test. RCC consists of clear cell $(75 \%)$, papillary $(10 \%)$, chromophobe $(5 \%)$ and other subtypes [10], and we first focused on clear cell carcinoma, the most common subtype of RCC. We discovered a significant increase of circulating plasma FN1 in patients with RCC and confirmed its significance in a larger patient cohort using a newly established measurement system.

\section{Materials and methods}

\subsection{Plasma samples}

Plasma samples were prospectively collected from RCC patients, prostate cancer patients and healthy volunteers at the Department of Urology, Kyushu University Hospital (Fukuoka, Japan) between October 2000 and January 2008. To exclude sampling bias, all the patients' whole blood $(7 \mathrm{ml})$ was collected in the same tube (EDTA-2Na tube, Venoject II, Terumo, Japan) before the surgery or first treatment. These blood samples were stored in $4^{\circ} \mathrm{C}$ for 1 hour and plasma was separated after centrifugation, aliquoted into $1 \mathrm{ml}$ samples in $1.5 \mathrm{ml}$ eppendorf tubes, and stored at $-80^{\circ} \mathrm{C}$. The control samples were collected and stored under the same condition. All the samples had the only one cycle of freeze-and-thaw. As we excluded the non-clear cell subtype and benign kidney tumors, the plasma from 77 histopathologically proven clear cell cancer patients were used for the analysis. Control plasma samples were randomly selected from 20 patients with prostate cancer and 130 healthy individuals after adjusting the age and gender. The clinical stage of each patient was classified according to the 7th edition UICC TNM classification [11]. Twenty RCC patients (excluding those in stage IV) were selected for analysis using 2DICAL in an effort to detect early stage biomarkers (Table 1).

\subsection{Ethics}

All individuals provided written informed consent authorizing the collection and use of their samples for research purposes. The protocol was reviewed and approved by the institutional ethics committee boards of the National Cancer Center Research Institute (Tokyo, Japan) and the Kyushu University (Fukuoka, Japan).

\section{3. $L C-M S$}

The 20 most abundant plasma proteins including albumin and immunoglobulin were removed using ProtPrep 20 Plasma Immunodepletion Kit (Sigma-Aldrich, St. Louis, MO) following the manufacturer's instructions. The depleted plasma samples were then digested with trypsin (Promega, Madison, WI) overnight at $37^{\circ} \mathrm{C}$. The resulting peptides were randomized and measured in triplicate by LC-MS. LC separation in a linear gradient of 0 to $80 \%$ acetonitrile in $0.1 \%$ formic acid at a speed of $200 \mathrm{~nL} /$ minute for 60 minutes was conducted using a splitless nano-flow HPLC system (Hitachi High-technologies, Tokyo, Japan). MS data were acquired every second for 60 minutes by an electrospray ionization mass spectrometer (Q-TOF U1tima; Waters, Milford, MC) directly linked to an LC in the range of $250-1600 \mathrm{~m} / \mathrm{z}$. MS peaks were detected, normalized, and quantified using the in-house 2DICAL software package as described previously [7]. A serial ID number was applied to each of the MS peaks detected (ID 1 to 23,407) [9]. The stability of LC-MS was monitored by calculating the correlation coefficient (CC) and coefficient of variance (CV) values among triplicate measurements.

\subsection{Protein identification by tandem mass spectrometry $(M S / M S)$}

Peak lists were generated using the Mass Navigator software package (version 1.2) (Mitsui Knowledge Industry, Tokyo, Japan) and searched against the SwissProt database (SwissProt_57.6.fast) using the Mascot software package (version 2.2.06) (Matrix Science, London, UK). The search parameters used were as follows: A database of human proteins was selected. 
Table 1

Clinicopathological characteristics of individuals examined in this study

\begin{tabular}{|c|c|c|c|c|c|c|}
\hline & & \multicolumn{3}{|c|}{ Cases anlyzed by AlphaLISA $(n=227)$} & \multicolumn{2}{|c|}{ Cases analyzed by 2DICAL $(n=60$} \\
\hline & & $\operatorname{RCC}(n=77)$ & $\mathrm{PCa}(\mathrm{n}=20)$ & Healthy $(n=130)$ & $\mathrm{RCC}(n=20)$ & Healthy $(n=20)$ \\
\hline Age & $($ mean $\pm \mathrm{SD})$ & $61.2 \pm 11.0$ & $64.8 \pm 6.9$ & $65.4 \pm 10.5$ & $63.8 \pm 8.5$ & $66.0 \pm 7.9$ \\
\hline \multicolumn{7}{|c|}{ Gender } \\
\hline & Male & 57 & 20 & 113 & 20 & 20 \\
\hline & Female & 20 & & 17 & 0 & 0 \\
\hline \multicolumn{7}{|c|}{ Clinical stage* } \\
\hline & I & 56 & 9 & & 17 & \\
\hline & II & 3 & 11 & & 2 & \\
\hline & III & 3 & & & 1 & \\
\hline & IV & 9 & & & 0 & \\
\hline & Unknown & 6 & & & & \\
\hline \multicolumn{7}{|c|}{ Tumor side } \\
\hline & Right & 38 & & & 11 & \\
\hline & Left & 39 & & & 9 & \\
\hline \multicolumn{7}{|c|}{ His tologic type } \\
\hline & Clear cell & 77 & & & 20 & \\
\hline & Chromophobe & 0 & & & 0 & \\
\hline & Papillary & 0 & & & 0 & \\
\hline & Unclassified & 0 & & & 0 & \\
\hline
\end{tabular}

RCC, renal cell carcinome; PCa, prostate cancer; AlphaLISA, amplified luminescence proximity homogeneous assay; 2DICAL, two-dimensional image convert

Trypsin was designated as the enzyme, and up to one missed cleavage was allowed. Mass tolerances for precursor and fragment ions were $\pm 0.2 \mathrm{Da}$ and $\pm 0.8 \mathrm{Da}$, respectively. The score threshold was set to the value over 20 for peptide search. If a peptide matched to multiple proteins, the protein name with the highest Mascot score was selected.

\subsection{Western blot analysis}

Plasma samples were fractionated with SDS-PAGE and electroblotted onto a polyvinylidene difluoride membrane (Millipore, Billerica, MA), as described previously $[9,12]$. Primary antibodies used were mouse monoclonal anti-FN1 antibody (R\&D Systems, Minneapolis, MN) and mouse monoclonal antibody against human complement C3b- $\alpha$ (PROGEN, Heidelberg, Germany) [8]. The membrane was then incubated with the primary antibody and subsequently with the relevant horseradish peroxidase-conjugated anti-mouse IgG as described previously. Blots were developed using an enhanced chemiluminescence (ECL plus) detection system (GE Healthcare, Buckinghamshire, UK).

\subsection{AlphaLISA}

An assay for measuring soluble FN1 was constructed using the AlphaLISA system (PerkinElmer, MA) which is a bead-bead nonradioactive technology. In brief, when a biological interaction brings the beads into close proximity, a cascade of chemical reactions is induced resulting in a greatly amplified signal, then a photosensitizer present in the beads converts ambient oxygen to a more excited singlet state upon laser excitation. Biotinylated rabbit polyclonal anti-FN1 antibody and mouse polyclonal anti-FN1 antibody were purchased from Abcam (Cambridge, UK). The AlphaLISA procedure was carried out according to the protocol provided by the manufacturer.

\subsection{Statistical methods}

The Mann-Whitney U-test was employed for statistical analysis of the correlation between RCC patients and controls as well as the plasma values of FN1 and clinicopathological parameters. Welch's $t$-test was employed for 2DICAL analysis. Kaplan-Meier analysis was used to examine the correlation of the plasma value of FN1, cancer-specific survival and overall survival. The area under the curve (AUC) of the receiver operating characteristic (ROC) was calculated to evaluate its diagnostic significance.

\section{Results}

\subsection{Identification of plasma proteins significantly increased in RCC patients}

Plasma proteins of 20 patients with RCC and 20 healthy individuals were digested by trypsin, and 
(a)
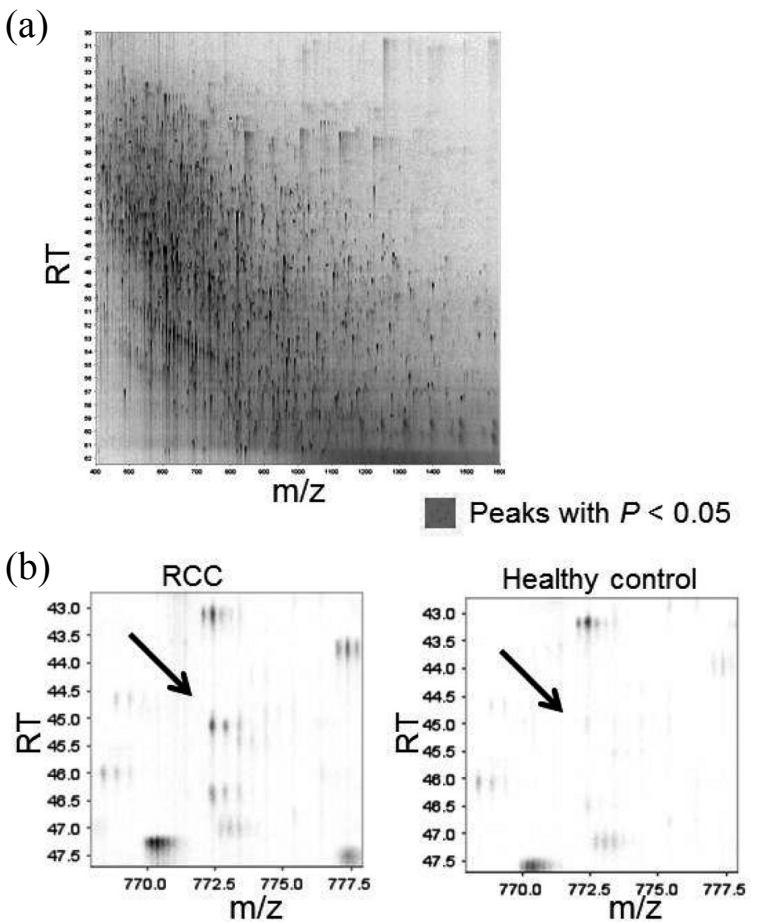

(c)

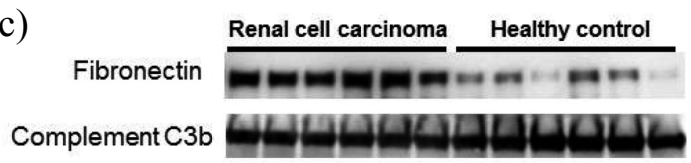

Fig. 1. (a) Two-dimensional display of all the MS peaks in 2DICAL. The 59 MS peaks whose mean intensity significantly differed in renal cell carcinoma patients from healthy controls $(p<0.05$, Welch's $t$-test) are highlighted in red. (b) Two representative MS peaks with the smallest $p$-value. RT; retention time. (c) Detection of plasma FN1 and complement C3b- $\alpha$ (loading control) by immunoblotting.

the resulting peptides were subjected to LC-MS. A total of 23,407 MS peaks per sample were detected in the range of $250-1,600 \mathrm{~m} / z$ and $25-65$ minutes across the 40 plasma samples, and their relative mass intensity was calculated using 2DICAL. The mean CC and CV values of the 23,407 MS peaks were over 0.95 and under 0.15 , respectively, confirming the high reproducibility of LC-MS. Among the 23,407 MS peaks we found that the mean intensity of 59 peaks (in triplicate) significantly differed between 20 RCC patients and 20 healthy controls $(p<0.05$, Welch's $t$-test). Thirty six peaks were increased and 23 peaks were decreased in RCC patients and the statistical significance was confirmed by calculating the false discovery rate (FDR) values [13] (data not shown). Figure 1a shows a representative 2-dimensional view in which all the $\sim 23,000$ MS peaks were displayed with the $m / z$ along the $\mathrm{X}$ axis and the $\mathrm{RT}$ of $\mathrm{LC}$ along the $\mathrm{Y}$ axis and the 59 MS peaks are highlighted in red. Figure $1 \mathrm{~b}$ shows a representative MS peak that increased in the plasma of RCC patients.

\subsection{Protein identification by $M S / M S$}

Fifty seven MS/MS spectra acquired from the $59 \mathrm{MS}$ peaks matched to 21 peptide sequences deposited in the human protein database (Table 2). Remarkably, 16 of the 21 peptides were found to be derived from the amino acid sequence of $F N 1$ gene product (Supportive information Figs S1 and S2). The identification and differential expression of FN1 protein were confirmed by immunoblotting (Fig. 1c).

\subsection{Verification by AlphaLISA}

To validate the increased level of plasma FN1, we constructed a new assay that can quantify the amount of FN1. The AlphaLISA showed high reproducibility with a median CV value of 0.08 among triplicates and linearity in the range of $50-800 \mu \mathrm{g} / \mathrm{ml}$.

The plasma concentration of FN1 was measured in 77 RCC patients, 20 prostate cancer (PCa) patients, and 130 healthy individuals by AlphaLISA. There was a significant difference between RCC patients (405 \pm $153 \mu \mathrm{g} / \mathrm{ml})$ and healthy individuals $(294 \pm 102 \mu \mathrm{g} / \mathrm{ml})$ with a $p$-value of $1.8 \times 10^{-7}$ (Mann-Whitney U test) (Fig. 2a). The plasma concentration of FN1 was not elevated in PCa patients $(306 \pm 81 \mu \mathrm{g} / \mathrm{ml})$. The AUC value of ROC for plasma FN1 concentration of RCC patients to healthy individuals was calculated to be 0.71 for all stages, stage I and II and stage III and IV (Fig. 2b). The optimum diagnostic cut-off point of FN1 was identified at $377 \mu \mathrm{g} / \mathrm{ml}$ by the AUC curve. At this point, sensitivity, specificity, PPV and NPV were $53 \%, 82 \%, 64 \%$ and $75 \%$ respectively. And the fibronectin concentration in each clinical stage was shown in Fig. $2 c$.

\subsection{Correlation of plasma concentration of FN1 and clinicopathological parameters}

The statistical analyses were performed to detect the correlation of plasma concentration of FN1 and clinical stage (Fig. 2c), but there were no significant differences. Also, there were no significant correlations between concentration of FN1 and the other clinicopathological parameters, such as tumor size, tumor grade and vascular involvement (data not shown). Furthermore, Kaplan-Meier analysis, used to analyze the correlation 
Table 2

Summary of protein identification by tandem mass spectrometry

\begin{tabular}{|c|c|c|c|c|c|c|c|c|c|}
\hline ID & $m / z$ & RT & Charge & $\begin{array}{c}\text { Control } \\
(\text { mean } \pm \text { SD) }\end{array}$ & $\begin{array}{c}\text { RCC } \\
(\text { mean } \pm \text { SD) }\end{array}$ & $P$ Values * * & Mascot Score & Peptide sequence & Protein description \\
\hline 2411 & 799.3815 & 36.479 & 3 & $15 \pm 6$ & $25 \pm 13$ & $5.09 \mathrm{E}-03$ & 84.46 & RPGGEPSPEGTTGQSYNQYSQR & Fibronectin \\
\hline 3454 & 622.3328 & 39.679 & 3 & $14 \pm 4$ & $20 \pm 8$ & $8.59 \mathrm{E}-03$ & 75.78 & HTSVQTTSSGSGPFTDVR & Fibronectin \\
\hline 3948 & 647.3662 & 49.283 & 2 & $13 \pm 2$ & $17 \pm 7$ & $9.54 \mathrm{E}-03$ & 54.92 & DLQFVEVTDVK & Fibronectin \\
\hline 2039 & 978.5337 & 47.716 & 2 & $16 \pm 7$ & $30 \pm 20$ & $6.08 \mathrm{E}-03$ & 53.45 & EESPLLIGQQSTVSDVPR & Fibronectin \\
\hline 750 & 706.3586 & 44.432 & 2 & $101 \pm 45$ & $73 \pm 28$ & $2.34 \mathrm{E}-02$ & 51.41 & KWQEEMELYR & Apolipoprotein A-I \\
\hline 2614 & 815.4614 & 46.26 & 2 & $11 \pm 4$ & $18 \pm 12$ & $1.61 \mathrm{E}-02$ & 50.73 & VDVIPVNLPGEHGQR & Fibronectin \\
\hline 2068 & 646.379 & 52.817 & 2 & $17 \pm 7$ & $26 \pm 15$ & $1.96 \mathrm{E}-02$ & 46.43 & GATYNIIVEALK & Fibronectin \\
\hline 2854 & 997.5346 & 53.967 & 2 & $18 \pm 5$ & $23 \pm 11$ & 4.61E-02 & 41.28 & NTFAEVTGLSPGVTYYFK & Fibronectin \\
\hline 1231 & 675.3681 & 45.847 & 2 & $28 \pm 11$ & $52 \pm 34$ & $4.38 \mathrm{E}-03$ & 40.93 & WLPSSSPVTGYR & Fibronectin \\
\hline 1816 & 772.8941 & 45.207 & 2 & $17 \pm 7$ & $32 \pm 20$ & $5.88 \mathrm{E}-03$ & 35.57 & SYTITGLQPGTDYK & Fibronectin \\
\hline 2439 & 638.3344 & 38.15 & 2 & $22 \pm 7$ & $30 \pm 13$ & $1.54 \mathrm{E}-02$ & 32.64 & HVVPNEVVVQR & Gelsolin \\
\hline 2569 & 555.8103 & 40.153 & 2 & $16 \pm 5$ & $25 \pm 13$ & $6.00 \mathrm{E}-03$ & 32.26 & STTPDITGYR & Fibronectin \\
\hline 1155 & 772.419 & 45.123 & 2 & $43 \pm 14$ & $64 \pm 34$ & $1.27 \mathrm{E}-02$ & 31.79 & SYTITGLQPGTDYK & Fibronectin \\
\hline 2771 & 701.8697 & 39.773 & 2 & $13 \pm 5$ & $22 \pm 13$ & $6.58 \mathrm{E}-03$ & 30.7 & HYQINQQWER & Fibronectin \\
\hline 2611 & 592.8548 & 43.895 & 2 & $26 \pm 11$ & $19 \pm 6$ & $1.87 \mathrm{E}-02$ & 30.31 & IQNILTEEPK & Serum paraoxonase \\
\hline 1371 & 511.785 & 35.131 & 2 & $44 \pm 12$ & $55 \pm 17$ & $1.82 \mathrm{E}-02$ & 29.99 & ATVVYQGER & Beta-2-glycoprotein 1 \\
\hline 1826 & 867.5129 & 50.364 & 2 & $20 \pm 7$ & $36 \pm 22$ & $3.48 \mathrm{E}-03$ & 29.17 & NLQPASEYTVSLVAIK & Fibronectin \\
\hline 1813 & 701.366 & 39.859 & 2 & $28 \pm 7$ & $42 \pm 18$ & $4.02 \mathrm{E}-03$ & 27.25 & HYQINQQWER & Fibronectin \\
\hline 2417 & 576.8117 & 42.453 & 2 & $16 \pm 5$ & $26 \pm 15$ & $5.75 \mathrm{E}-03$ & 26.67 & FTNIGPDTMR & Fibronectin \\
\hline 1794 & 964.0527 & 58.428 & 2 & $23 \pm 8$ & $34 \pm 20$ & 2.61E-02 & 23.59 & VTWAPPPSIDLTNFLVR & Fibronectin \\
\hline 1377 & 629.36 & 53.672 & 2 & $39 \pm 23$ & $24 \pm 9$ & 7.97E-03 & 21.25 & DLAVVDAKDAIK & EXOC1_HUMAN \\
\hline
\end{tabular}

RT, retention time; RCC, renal cell carcinoma

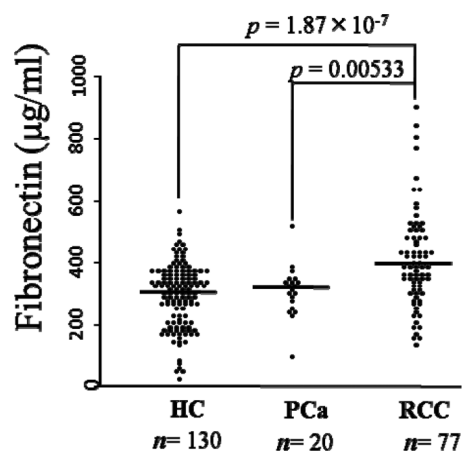

(a)

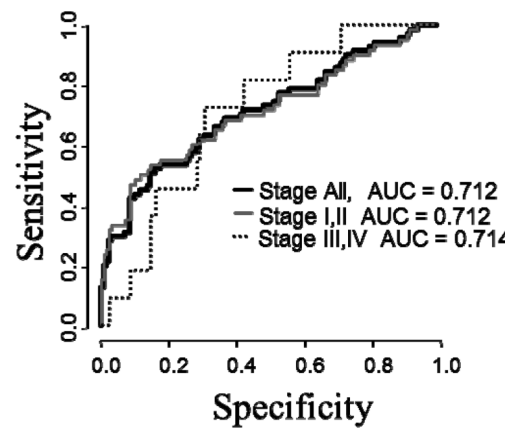

(b)

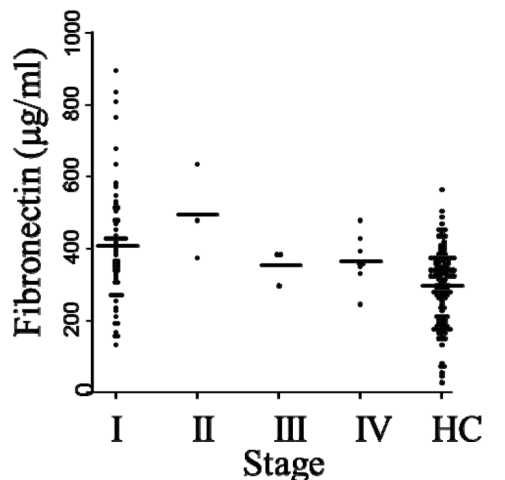

(c)

Fig. 2. (a) Concentration of plasma FN1 in each group. The FN1 concentration of renal cell carcinoma patients $(n=77)$, healthy individuals $(n=130)$ and prostate cancer patients $(n=20)$ was measured by AlphaLISA. There were significant differences in renal cell carcinoma patients compared to healthy individuals and prostate cancer patients, but not between healthy individuals and prostate cancer patients (Mann-Whitney U test). Horizontal lines represent the average concentration. (b) Receiver operating characteristic (ROC) curve for plasma FN1 concentration. AUC value of ROC for plasma FN1 concentration of RCC patients to healthy individuals was calculated to be 0.71 for all stages, stage I and II and stage III and IV. Similar AUC value of earlier stage to advanced stage suggested the possibility of early detection of renal cell carcinoma by plasma FN1. (c) The plasma FN1 concentration in each clinical stage. HC; healthy control.

of serum value of FN1, cancer-specific survival and overall survival, failed to prove any statistical significant differences with a median follow up of 47.6 months after surgery (data not shown).

\section{Discussion}

FN1 is a high-molecular-weight extracellular matrix protein that plays an important role in cellular at- tachment and cell spread [14,15]. FN1 can be soluble or insoluble, is produced by hepatocytes and various cell types and is bound to integrins [16]. Altered expression of FN1 is known to change the morphology of several tumor cell lines [17]. In several studies of different RCC cell lines, FN1 was shown to be secreted into the culture medium and suggested to influence the movement and invasion of these cells [1820]. Another study showed FN1 plasma levels signif- 
icantly elevated in localized and metastatic RCC patients compared to a control group [21]. According to "THE HUMAN PROTEIN ATLAS" (http://www. proteinatlas.org/ENSG00000115414), FN1 is expressed in extracellular matrix and stromal cell. FN1 is expressed weakly in normal kidney and relatively higher expressed in kidney cancer. It could be considerable that higher plasma levels of FN1 is secreted from these extracellular matrix and stromal cell in kidney cancer. A recent study suggested that FN1 mRNA expression was higher in RCC compared to normal renal tissue and correlated with advanced disease, suggesting that FN1 mRNA expression might serve as a marker for RCC aggressiveness [22]. Although the researchers failed to measure the plasma concentration of FN1, this study supports the results described herein obtained by proteome based screening.

The results of plasma FN1 from 2DICAL analysis were validated in a hundreds-scale cohort using a different methodology. AlphaLISA confirmed that the plasma level of FN1 was up-regulated in the early stage of RCC, which suggested that the FN1 plasma levels might be a tool for screening and diagnosis of RCC. However, there a limitation to introduce FN1 for screening of RCC, because plasma concentrations between patients and controls were overlapped extensively, and FN1 was not examined in benign renal tumors.

RCC comprises five histologically distinct subtypes classified by morphologic and pathologic features including clear cell (75\%), papillary (10-15\%), chromophobe (5-10\%), collecting duct, and unclassified subtypes. We have previously reported that each RCC subtype has a totally different genetic profile by whole genome SNP array [10]. Therefore, each subtype should have a specific biomarker. In this study, we focused on clear cell RCC because it is the most abundant subtype of RCC and hence should be a first target of screening. Our comprehensive study of proteomics led to the possibility that monitoring the level of plasma FN1 could be clinically useful for the screening and diagnosis of RCC patients. The most of the patients we analyze were clinical stage I (56 cases / total 77 cases), and they had no symptoms such as febrile and showed normal range of C-reactive protein. Therefore, we believe that FN1 was not derived from acute phase reaction. Reports of the elevation of the plasma level of FN1 in RCC exist in the literature [21], but its clinical usage has not yet been described. One of the reasons may be the lack of applicable clinical test such as ELISA for FN1. The assessment of plasma FN1 levels must be determined for a large scale clinical cohort, but the construction of an easy clinical test such as ELISA will be needed for its completion.

\section{Acknowledgments}

We thank Ms. Ayako Igarashi, Ms. Tomoko Umaki, and Ms. Yuka Nakamura for their technical assistance.

\section{Disclosure of potential conflicts of interest}

These sponsors had no role in the design of the study, the collection of the data, the analysis and interpretation of the data, the decision to submit the manuscript for publication, or the writing of the manuscript.

\section{Grant supports}

Funding was received from the Program for Promotion of Fundamental Studies in Health Sciences conducted by the National Institute of Biomedical Innovation of Japan, and the Third-Term Comprehensive Control Research for Cancer and Research on Biological Markers for New Drug Development conducted by the Ministry of Health, Labour and Welfare of Japan.

\section{Conflicts of interest}

None.

\section{References}

[1] S.H. Landis, T. Murray, S. Bolden, P.A. Wingo. Cancer statistics, 1999, CA Cancer J Clin 49 (1999), 8-31.

[2] A.J. Schrader, Z. Varga, A. Hegele, S. Pfoertner, P. Olbert, R. Hofmann. Second-line strategies for metastatic renal cell carcinoma: classics and novel approaches, J Cancer Res Clin Oncol 132 (2006), 137-149.

[3] B.I. Rini, S. Halabi, R. Barrier, K.A. Margolin, D. Avigan, T. Logan et al. Adoptive immunotherapy by allogeneic stem cell transplantation for metastatic renal cell carcinoma: a CALGB intergroup phase II study, Biol Blood Marrow Transplant 12 (2006), 778-785.

[4] C. Gouttefangeas, A. Stenzl, S. Stevanovic, H.G. Rammensee. Immunotherapy of renal cell carcinoma, Cancer Immunol Immunother 56 (2007), 117-128.

[5] M. Remzi, M. Marberger. Renal tumor biopsies for evaluation of small renal tumors: why, in whom, and how? Eur Urol 55 (2009), 359-367.

[6] M. Ono, M. Shitashige, K. Honda, T. Isobe, H. Kuwabara, H. Matsuzuki et al. Label-free quantitative proteomics using large peptide data sets generated by nanoflow liquid chromatography and mass spectrometry, Mol Cell Proteomics 5 (2006), 1338-1347. 
[7] M. Ono, J. Matsubara, K. Honda, T. Sakuma, T. Hashiguchi, H. Nose et al. Prolyl 4-hydroxylation of alpha-fibrinogen: a novel protein modification revealed by plasma proteomics, $\mathrm{J}$ Biol Chem 284 (2009), 29041-29049.

[8] A. Negishi, M. Ono, Y. Handa, H. Kato, K. Yamashita, K. Honda et al. Large-scale quantitative clinical proteomics by label-free liquid chromatography and mass spectrometry, Cancer Sci 100 (2009), 514-519.

[9] J. Matsubara, M. Ono, A. Negishi, H. Ueno, T. Okusaka, J. Furuse et al. Identification of a predictive biomarker for hematologic toxicities of gemcitabine, J Clin Oncol 27 (2009), 2261-2268.

[10] A. Yokomizo, K. Yamamoto, K. Furuno, M. Shiota, K. Tatsugemi, K. Kuroiwa et al. Histopathologic subtype-specific genomic profiles of renal cell carcinomas identified by highresolution whole-genome single nucleotide polymorphism array analysis, Oncol Lett 1 (2010), 1073-1078.

[11] TNM Classification of Malignant Tumours. John Wiley and Sons Ltd 2009.

[12] M. Shitashige, R. Satow, K. Honda, M. Ono, S. Hirohashi, T. Yamada. Regulation of Wnt signaling by the nuclear pore complex, Gastroenterology 134 (2008), 1961-1971, 1971 e19611964.

[13] J.D. Storey, R. Tibshirani. Statistical significance for genomewide studies, Proc Natl Acad Sci USA 100 (2003), 9440-9445.

[14] S.M. Albelda. Role of integrins and other cell adhesion molecules in tumor progression and metastasis, Lab Invest 68 (1993), 4-17.

[15] R.O. Hynes, K.M. Yamada. Fibronectins: multifunctional modular glycoproteins, J Cell Biol 95 (1982), 369-377.

[16] R. Pankov, K.M. Yamada. Fibronectin at a glance, J Cell Sci 115 (2002), 3861-3863.

[17] H. Ro. Fibronectins. Berlin, Heidelberg, New York: Springer.

[18] W. Brenner, S. Gross, F. Steinbach, S. Horn, R. Hohenfellner, J.W. Thuroff. Differential inhibition of renal cancer cell invasion mediated by fibronectin, collagen IV and laminin, Cancer Lett 155 (2000), 199-205.

[19] J. Lohi, T. Tani, I. Leivo, A. Linnala, L. Kangas, R.E. Burgeson et al. Expression of laminin in renal-cell carcinomas, renalcell carcinoma cell lines and xenografts in nude mice, Int $\mathbf{J}$ Cancer 68 (1996), 364-371.

[20] J. Murata, I. Saiki, J. Yoneda, I. Azuma. Differences in chemotaxis to fibronectin in weakly and highly metastatic tumor cells, Jpn J Cancer Res 83 (1992), 1327-1333.

[21] A. Hegele, A. Heidenreich, J. Kropf, R. von Knobloch, Z. Varga, R. Hofmann et al. Plasma levels of cellular fibronectin in patients with localized and metastatic renal cell carcinoma, Tumour Biol 25 (2004), 111-116.

[22] S. Waalkes, F. Atschekzei, M.W. Kramer, J. Hennenlotter, G. Vetter, J.U. Becker et al. Fibronectin 1 mRNA expression correlates with advanced disease in renal cancer, BMC Cancer 10 (2010), 503. 
Supplemental material

MS/MS Fragmentation of RPGGEPSPEGTTGQSYNQYSQR

Found in FINC_HUMAN, Fibronectin OS=Homo sapiens GN=FN1 PE=1 SV=3

Match to Query 1: 2395.118583 from(799.380137,3+)

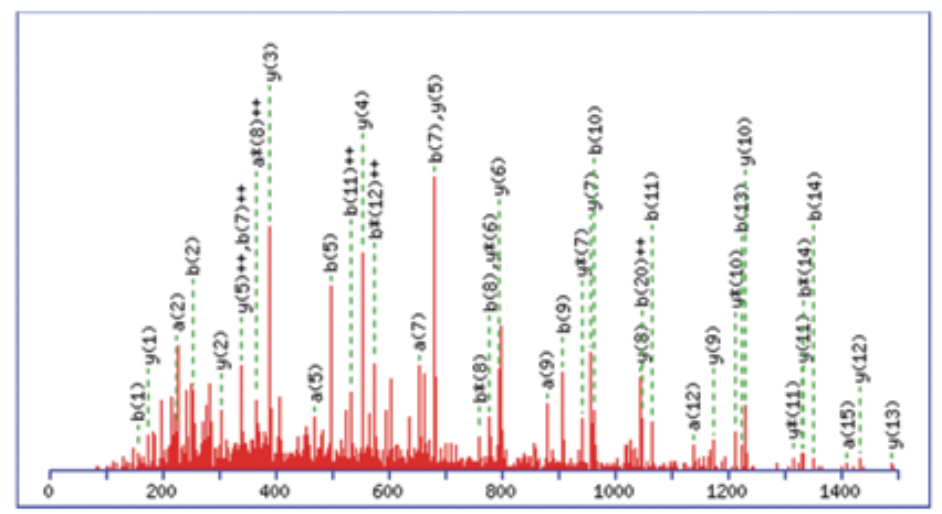

Monoisotopic mass of neutral peptide $\operatorname{Mr}$ (calc): 2395.0789

Ions Score: 84 Expect: $6.3 \mathrm{e}-008$

Matches (Bold Red): 41/252 fragment ions using 78 most intense peaks

\begin{tabular}{|c|c|c|c|c|c|c|c|c|c|c|c|c|c|c|}
\hline$\#$ & a & $\mathbf{a}^{++}$ & $a^{*}$ & $a^{w^{++}}$ & b & $\mathbf{b}^{++}$ & $\mathbf{b}^{*}$ & $\mathbf{b}^{\mathbf{4 + +}}$ & Seq. & $y$ & $y^{++}$ & $y^{*}$ & $y^{w^{++}}$ & $\#$ \\
\hline 1 & 129.1135 & 65.0604 & 112.0869 & 56.5471 & 157.1084 & 79.0578 & 140.0818 & 70.5446 & $\mathbf{R}$ & & & & & 22 \\
\hline 2 & & 113.5868 & 209.1397 & 105.0735 & & 127.5842 & & 119.0709 & & 2239.985 & & 2222.9585 & 829 & 21 \\
\hline 3 & & & & & & & & & G & & & & & 20 \\
\hline 4 & 340.2092 & 70.6082 & 323.1 & & 368.2 & 184.6057 & 351.1775 & 176.0924 & G & & & & & 19 \\
\hline 5 & 469.2518 & 35.1295 & 452.2252 & 226.6162 & 497. & 249.127 & & 240 . & E & & 101 & 2011 & 5.435 & 18 \\
\hline 6 & 566. & & & & & 297. & & & & & & & & 17 \\
\hline 7 & 653. & 719 & & & & 341. & & & $\mathrm{~S}$ & & & & & 16 \\
\hline 8 & 750.3893 & 375.6983 & & & & & & & $\mathbf{P}$ & & & & & 15 \\
\hline 9 & 879. & 440. & 862 & 431.7063 & 907 & 454 & & 445 & $\mathbf{E}$ & & & & & 14 \\
\hline 10 & 936. & 303 & & & & 482. & & & & & & & & 13 \\
\hline 11 & 1037.501 & 519.2542 & 1020.4745 & 510.7409 & 1065.496 & 533. & & 52 & $T$ & & & & 129 & 12 \\
\hline 12 & 1138.5487 & & & & & & & & & & & & & 11 \\
\hline 13 & & 887 & & & & & & & $\mathrm{C}$ & & & & & 10 \\
\hline 14 & 1323.6288 & & & & & & & & Q & & & & & \\
\hline 15 & 1410.6608 & & 1393.6342 & 697.3208 & 1438.6 & 719. & & 3182 & $\mathbf{S}$ & 1045 & 2385 & & & 8 \\
\hline 16 & & & & & & & & & 1 & & & & & \\
\hline 17 & & & & & & & & & & & 398.1908 & & & \\
\hline 18 & 1815.8256 & 908.4165 & 1798.7991 & 899.9032 & 1843.8205 & 922.4139 & 1826.794 & 913.9006 & Q & 681.3315 & \begin{tabular}{|l|}
341.1694 \\
\end{tabular} & 664.3049 & 332.6561 & \\
\hline
\end{tabular}

Fig. S1. Mascot report of one representative fragment of FN1. 
1 MLRGPGPGLL LLAVQCLGTA VPSTGASKSK RQAQQMVQPQ SPVAVSQSKP 51 GCYDNGKHYQ INQQWERTYL GNALVCTCYG GSRGFNCESK PEAEETCFDK 101 YTGNTYRVGD TYERPKDSMI WDCTCIGAGR GRISCTIANR CHEGGQSYKI

151 GDTWRRPHET GGYMLECVCL GNGKGEWTCK PIAEKCFDHA AGTSYVVGET

201 WEKPYQGWMM VDCTCLGEGS GRITCTSRNR CNDQDTRTSY RIGDTWSKKD

251 NRGNLLQCIC TGNGRGEWKC ERHTSVQTTS SGSGPFTDVR AAVYQPQPHP

301 QPPPYGHCVT DSGVVYSVGM QWLKTQGNKQ MLCTCLGNGV SCQETAVTQT

351 YGGNSNGEPC VLPFTYNGRT FYSCTTEGRQ DGHLWCSTTS NYEQDQKYSE

401 CTDHTVLVQT QGGNSNGALC HFPFLYNNHN YTDCTSEGRR DNMKWCGTTQ

451 NYDADQKFGF CPMAAHEEIC TTNEGVMYRI GDQWDKQHDM GHMMRCTCVG

501 NGRGEWTCIA YSQLRDQCIV DDITYNVNDT FHKRHEEGHM LNCTCFGQGR

551 GRWKCDPVDQ CQDSETGTFY QIGDSWEKYV HGVRYQCYCY GRGIGEWHCQ

601 PLQTYPSSSG PVEVFITETP SQPNSHPIQW NAPQPSHISK YILRWRPKNS

651 VGRWKEATIP GHLNSYTIKG LKPGVVYEGQ LISIQQYGHQ EVTRFDFTTT

701 STSTPVTSNT VTGETTPFSP LVATSESVTE ITASSFVVSW VSASDTVSGF

751 RVEYELSEEG DEPQYLDLPS TATSVNIPDL LPGRKYIVNV YQISEDGEQS

801 LILSTSQTTA PDAPPDPTVD QVDDTSIVVR WSRPQAPITG YRIVYSPSVE

851 GSSTELNLPE TANSVTLSDL QPGVQYNITI YAVEENQEST PVVIQQETTG

901 TPRSDTVPSP RDLQFVEVTD VKVTIMWTPP ESAVTGYRVD VIPVNLPGEH

951 GQRLPISRNT FAEVTGLSPG VTYYFKVFAV SHGRESKPLT AQQTTKLDAP

1001 TNLQFVNETD STVLVRWTPP RAQITGYRLT VGLTRRGQPR QYNVGPSVSK

1051 YPLRNLQPAS EYTVSLVAIK GNQESPKATG VFTTLQPGSS IPPYNTEVTE

1101 TTIVITWTPA PRIGFKLGVR PSQGGEAPRE VTSDSGSIVV SGLTPGVEYV

1151 YTIQVLRDGQ ERDAPIVNKV VTPLSPPTNL HLEANPDTGV LTVSWERSTT

1201 PDITGYRITT TPTNGQQGNS LEEVVHADQS SCTFDNLSPG LEYNVSVYTV

1251 KDDKESVPIS DTIIPAVPPP TDLRFTNIGP DTMRVTWAPP PSIDLTNFLV

1301 RYSPVKNEED VAELSISPSD NAVVLTNLLP GTEYVVSVSS VYEQHESTPL

1351 RGRQKTGLDS PTGIDESDIT ANSFTVHWIA PRATITGYRI RHHPEHFSGR

1401 PREDRVPHSR NSITLTNLTP GTEYVVSIVA LNGREESPLL IGQQSTVSDV

1451 PRDLEVVAAT PTSLLISWDA PAVTVRYYRI TYGETGGNSP VQEFTVPGSK

1501 STATISGLKP GVDYTITVYA VTGRGDSPAS SKPISINYRT EIDKPSQMQV

1551 TDVQDNSISV KWLPSSSPVT GYRVTTTPKN GPGPTKTKTA GPDQTEMTIE

1601 GLQPTVEYVV SVYAQNPSGE SQPLVQTAVT NIDRPKGLAF TDVDVDSIKI

1651 AWESPQGQVS RYRVTYSSPE DGIHELFPAP DGEEDTAELQ GLRPGSEYTV

1701 SVVALHDDME SQPLIGTQST AIPAPTDLKF TQVTPTSLSA QWTPPNVQLT

1751 GYRVRVTPKE KTGPMKEINL APDSSSVVVS GLMVATKYEV SVYALKDTLT

1801 SRPAQGVVTT LENVSPPRRA RVTDATETTI TISWRTKTET ITGFQVDAVP

1851 ANGQTPIQRT IKPDVRSYTI TGLQPGTDYK IYLYTLNDNA RSSPVVIDAS

1901 TAIDAPSNLR FLATTPNSLL VSWQPPRARI TGYIIKYEKP GSPPREVVPR

1951 PRPGVTEATI TGLEPGTEYT IYVIALKNNQ KSEPLIGRKK TDELPQLVTL

2001 PHPNLHGPEI LDVPSTVQKT PEVTHPGYDT GNGIQLPGTS GQQPSVGQQM

2051 IFEEHGFRRT TPPTTATPIR HRPRPYPPNV GEEIQIGHIP REDVDYHLYP

2101 HGPGLNPNAS TGQEALSQTT ISWAPFQDTS EYIISCHPVG TDEEPLQFRV

2151 PGTSTSATLT GLTRGATYNI IVEALKDQQR HKVREEVVTV GNSVNEGLNQ

2201 PTDDSCFDPY TVSHYAVGDE WERMSESGFK LLCQCLGFGS GHFRCDSSRW

2251 CHDNGVNYKI GEKWDRQGEN GQMMSCTCLG NGKGEFKCDP HEATCYDDGK

2301 TYHVGEQWQK EYLGAICSCT CFGGQRGWRC DNCRRPGGEP SPEGTTGQSY

2351 NQYSQRYHQR TNTNVNCPIE CFMPLDVQAD REDSRE

\section{Matched peptides shown in Bold Red}

Fig. S2. Peptide hits in the FN1 sequence indicated in red. 